TITLE:

\title{
Synthesis of Phenylcyclopropane- Based Secondary Amine Catalysts and Their Applications in Enamine Catalysis
}

\section{$\operatorname{AUTHOR(S):~}$}

Takeshima, Aika; Kano, Taichi; Maruoka, Keiji

\section{CITATION:}

Takeshima, Aika ... [et al]. Synthesis of Phenylcyclopropane-Based Secondary Amine

Catalysts and Their Applications in Enamine Catalysis. Organic Letters 2019, 21: 8071-8074

ISSUE DATE:

2019-10-04

URL:

http://hdl.handle.net/2433/244237

\section{RIGHT:}

This document is the Accepted Manuscript version of a Published Work that appeared in final form in Organic Letters, copyright ( ) American Chemical Society after peer review and technical editing by the publisher. To access the final edited and published work see https://doi.org/10.1021/acs.orglett.9b03070:; The full-text file will be made open to the public on 12 September 2020 in accordance with publisher's 'Terms and Conditions for Self-Archiving'., この論文は出版 社版でありません。引用の際には出版社版をご確認ご利用ください。; This is not the published version. Please cite

only the published version. 


\title{
Synthesis of Phenylcyclopropane-Based Secondary Amine Catalysts and Their Applications in Enamine Catalysis
}

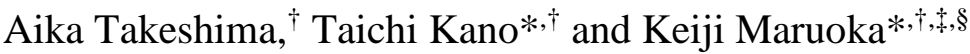 \\ ${ }^{\dagger}$ Department of Chemistry, Graduate School of Science, Kyoto University, Sakyo, Kyoto 606-8502, Japan \\ ${ }^{\ddagger}$ Department of Organocatalytic Chemistry, Graduate School of Pharmaceutical Sciences, Kyoto University, Sakyo, Kyoto \\ 606-8501, Japan \\ ${ }^{\S}$ School of Chemical Engineering and Light Industry, Guangdong University of Technology, Guangzhou 510006, China \\ Supporting Information Placeholder
}
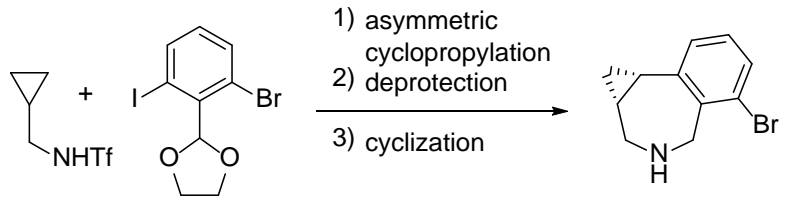

\begin{abstract}
A novel chiral motif based on a phenylcyclopropane scaffold has been designed and a facile synthetic route to the keyintermediate for the synthesis of phenylcyclopropane-based chiral secondary amines has been developed. Newly synthesized chiral amines function as effective catalysts for several asymmetric reactions through enamine intermediates.
\end{abstract}

In asymmetric catalysis, the design of novel chiral motif is highly important for the development of new chiral ligands or catalysts providing unprecedented reactivity and selectivity. Among them, the axially chiral binaphthyl structure has been widely applied to chiral ligands such as BINAP, BINOL or various catalysts. ${ }^{1}$ We have previously designed binaphthyl-based secondary amine catalysts $(S)-\mathbf{1}$ and $(S)-2$ containing an acid functional group at the 3-position for enamine catalysis (Figure $1)^{2-4}$ These catalysts have been successfully utilized in several asymmetric reactions, and have shown unique reactivity and selectivity in comparison with commonly used proline and its derivatives. 3-Mono-substituted binaphthyl-based secondary amine structures were also found in amine organocatalysts $(S)$ 3 and $(S)-4 .^{5}$ In spite of their utility, however, the applications of binaphthyl-based amines in asymmetric reactions are still rare due to their synthetic inefficiency. Since the axially chiral binaphthyl dicarboxylic acid (S)-5 is not readily available, the binaphthyl-based secondary amine (S)-6 as a key-intermediate for our catalysts is less accessible. ${ }^{6}$ In connection with our interest in asymmetric reactions promoted by chiral secondary amines, we have developed a novel chiral motif $(S, R)-7$ based on a phenylcyclopropane scaffold that can be prepared through scalable processes using readily available and inexpensive reagents (Scheme 1). In designing this motif, the one naphthalene moiety of the previous binaphthyl-based amine is replaced with a cyclopropane ring as it is considered to be an isostere of olefin in medicinal chemistry. ${ }^{7}$ The modular nature of this motif allows quick access to several secondary amine catalysts. This new family of catalysts opens up opportunities for the exploration of new reactions and also the development of highly effective catalysts for known reactions. We report herein the simple and efficient synthesis of phenylcyclopropane-based secondary amine catalysts and their applications to the asymmetric reactions through enamine intermediates.

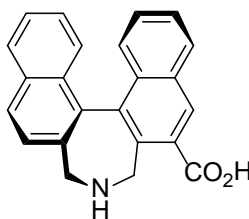

(S)-1

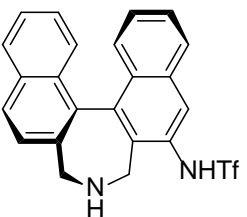

(S)-2

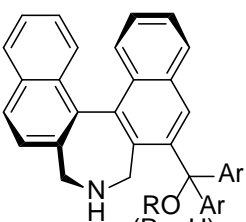

S) $3(\mathrm{R}=\mathrm{H})$

(S) -4

$\left(\mathrm{Ar}=3,5-\left(\mathrm{CH}_{3}\right)_{2}-\mathrm{C}_{6} \mathrm{H}_{3}\right)$

Kano \& Maruoka (ref 2) Kano \& Maruoka (ref 3) Lu (ref 5)
Figure 1. Binaphthyl-based organocatalysts.

Scheme 1. Design of a Novel Chiral Secondary Amine Motif

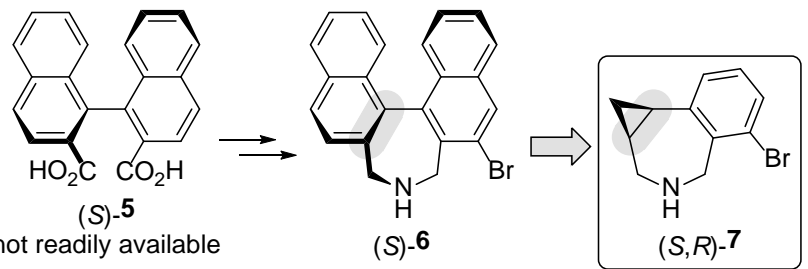

Synthesis of chiral secondary amine 7 commenced with the preparation of acetal 9 by treatment of 2-bromo-6-iodobenzaldehyde $(\mathbf{8})^{8}$ with ethylene glycol in the presence of $p$-toluenesulfonic acid monohydrate. The palladium-catalyzed 
asymmetric cyclopropylation of the obtained 9 with $N$-cyclopropylmethyl triflamide $\mathbf{1 0}$ gave the desired phenylcyclopropane $(R, S)-12$ in excellent enantioselectivity, albeit with moderate yield. ${ }^{9}$ Removal of trifluoromethanesulfonyl group and subsequent acidic work-up provided the cyclic imine, which was reduced with $\mathrm{NaBH}_{4}$ to the cyclic amine $(R, S)-7$ (Scheme 2).

\section{Scheme 2. Synthesis of Chiral Secondary Amine (R,S)-7}
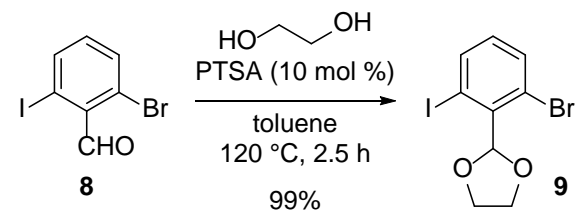

$$
{ }^{i-\mathrm{Pr}} \underset{\mathrm{C}_{2} \mathrm{H}}{\mathrm{NHBOC}}
$$

$$
\bigvee_{10}
$$

$(10 \mathrm{~mol} \%)$

(S)-11

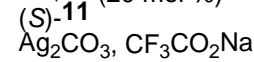

$\mathrm{mol} \%)$ $t$-BuOH, $80^{\circ} \mathrm{C}$, air, $19 \mathrm{~h}$

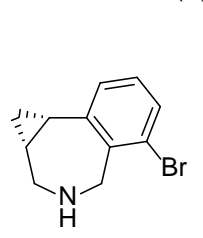

$(R, S)^{-7}$

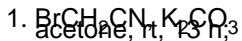

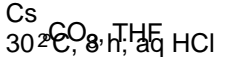

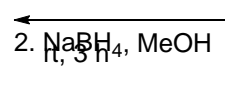

$63 \%$ (2 steps) 51\%, $99 \%$ ee

With the key-intermediate $(R, S)-7$ in hand several chiral secondary amine catalysts could be synthesized after the protection of the amino group by benzyloxycarbonyl (Cbz) group (Scheme $3)$. After the palladium-catalyzed amination of $(R, S)-\mathbf{1 3}$ with benzophenone imine, ${ }^{10}$ treatment with $\mathrm{Tf}_{2} \mathrm{O}$ and deprotection afforded trifluoromethanesulfonamide $(R, S)-\mathbf{1 4}$ in $77 \%$ yield. The chiral amino alcohol $(R, S)-\mathbf{1 5}$ was prepared by treatment of lithiated $(R, S)$-13 with benzophenone and subsequent deprotection. Treatment of $(R, S)$-15 with trimethylsilyl triflate gave the chiral amine $(R, S)-\mathbf{1 6}$. Finally, the chiral amine catalyst $(R, S)$ 17 was synthesized through debromination of $(R, S)-\mathbf{1 3}$.

Scheme 3. Synthesis of a Series of PhenylcyclopropaneBased Secondary Amine Catalysts ${ }^{a}$<smiles>Brc1cccc2c1CNC[C@@H]1CC21</smiles>

$(R, S)-7$

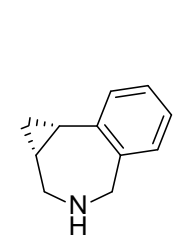

$(R, S)-17$<smiles>CC(=O)N1Cc2c(Br)cccc2[C@H]2C[C@H]2C1</smiles>

$(R, S)-13$

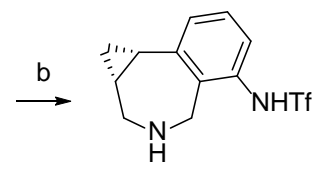

$(R, S)-14$

$$
\downarrow \mathrm{e} \downarrow \mathrm{c}
$$

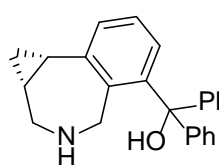

$(R, S)-15$

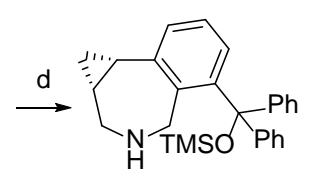

$(R, S)-16$
aReagents and conditions: (a) Cbz-Cl, Et 3 N, THF, rt (99\%); (b) (i) benzophenone imine, $\mathrm{Pd}_{2}(\mathrm{dba})_{3}$, BINAP, NaOt-Bu, toluene, reflux, then $1 \mathrm{~N} \mathrm{HCl}$, THF, reflux; (ii) $\mathrm{Tf}_{2} \mathrm{O}, N, N$-dimethylaniline, $\mathrm{CH}_{2} \mathrm{Cl}_{2}$, rt; (iii) $\mathrm{H}_{2}, \mathrm{Pd} / \mathrm{C}, \mathrm{MeOH}, 40{ }^{\circ} \mathrm{C}$ (77\% for three steps); (c) (i) $\mathrm{BuLi}$, THF, $-78^{\circ} \mathrm{C}$; benzophenone, $0^{\circ} \mathrm{C}(59 \%)$; (ii) $\mathrm{H}_{2}, \mathrm{Pd}(\mathrm{OH})_{2}, \mathrm{MeOH}$, rt (81\%); (d) TMSOTf, Et $3 \mathrm{~N}, \mathrm{CH}_{2} \mathrm{Cl}_{2}$, rt (92\%); (e) $\mathrm{H}_{2}, \mathrm{Pd}(\mathrm{OH})_{2}$, $\mathrm{Et}_{3} \mathrm{~N}, \mathrm{THF}, \mathrm{rt}(64 \%)$.
The absolute configurations of chiral amino sulfonamide 14 were determined by X-ray crystal structure analysis of $\mathrm{HCl}$ salt of 14 (Figure 2). It was found that the spatial relationship between two nitrogen atoms of $\mathbf{1 4}$ closely resembles that of the binaphthyl-based amino sulfonamide catalyst $(R)-2 .{ }^{11,12}$ front view

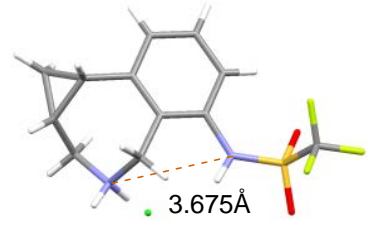

bottm view

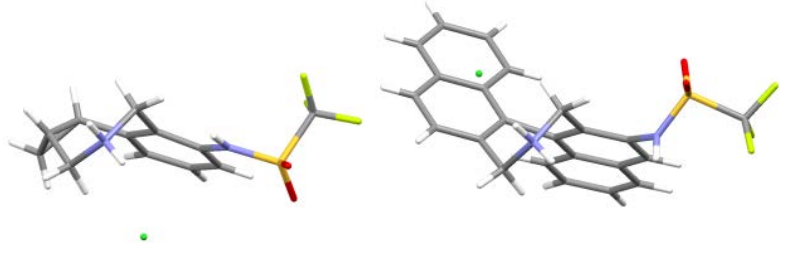

Figure 2. X-ray crystal structures of $(R, S)-\mathbf{1 4} \cdot \mathrm{HCl}$ salt and $(R)$ $2 \cdot \mathrm{HCl}$ salt.

Proline and its derivatives are known to promote the syn-selective Mannich reaction of aldehydes with imines. ${ }^{13}$ On the other hand, the newly synthesized $(R, S)-\mathbf{1 4}$ was found to effectively catalyze the anti-selective Mannich reaction between isovaleraldehyde and an $\alpha$-imino ester 18 to give the corresponding anti-Mannich adduct 19 with excellent enantioselectivity (Scheme 4a). ${ }^{3 a, 13 f, 13 g}$ The Mannich reaction using $N$-Boc-protected imine $\mathbf{2 0}$ also gave the unusual anti-adduct $\mathbf{2 1}$ in good yield with high enantioselectivity (Scheme $4 \mathrm{~b}) .{ }^{3 \mathrm{~b}}$ Since the phenylcyclopropane-based amino sulfonamide catalyst $(R, S)-\mathbf{1 4}$ behaves similarly to the binaphthyl-based catalyst $(R)$-2, utility of the phenylcyclopropane scaffold as a novel chiral motif has been evaluated in several other amine-catalyzed reactions. We found that $(R, S)-\mathbf{1 4}$ was an effective catalyst for the asymmetric aminoxylation of 3-phenylpropanal with nitrosobenzene, and in-situ reduction of the product with $\mathrm{NaBH}_{4}$ gave 1,2-diol derivative 22 in excellent enantioselectivity (Scheme 4c). ${ }^{14,15}$ On the other hand, use of chiral amino alcohol $(R, S)-\mathbf{1 5}$ as catalyst afforded the optically enriched hydroxyamination product 23 exclusively from the same set of reactants (Scheme 4d). ${ }^{16,17}$ Several chiral amine catalysts were applied to the conjugate addition of 3-phenylpropanal to nitrostyrene, and $(R, S)-\mathbf{1 6}$ bearing a bulky diphenyl(trimethylsiloxy)methyl group provided the corresponding conjugate adduct $\mathbf{2 4}$ in good yield with high enantioselectivity (Scheme 4e). ${ }^{5,18}$ Additionally, $(R, S)$-16 proved to be an appropriate catalyst for the conjugate addition to enone 25, giving ketone $\mathbf{2 7}$ with satisfactory yield and stereoselectivity after olefination of the resulting conjugate adduct with $\mathbf{2 6}$ (Scheme 4f). ${ }^{19}$ 
Scheme 4. Asymmetric Reactions Catalyzed by Phenylcyclopropane-Based Amines

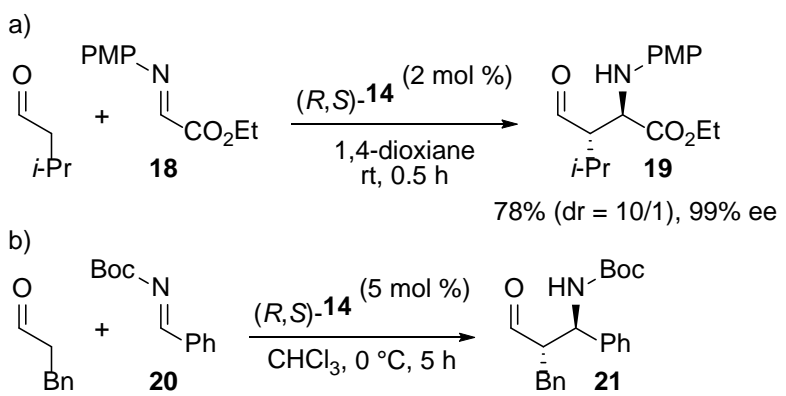

$80 \%(d r=5.6 / 1), 98 \%$ ee

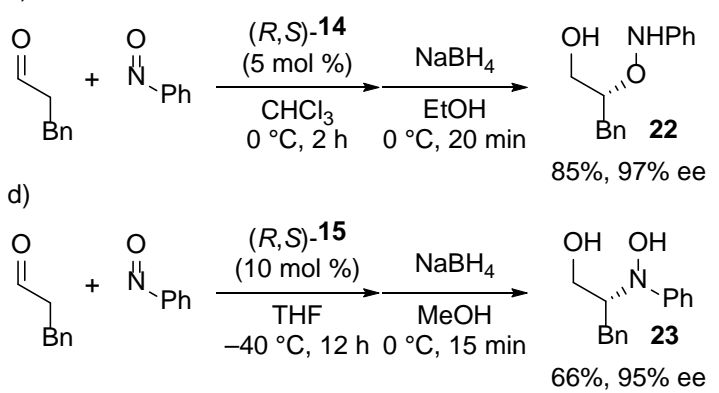

e)
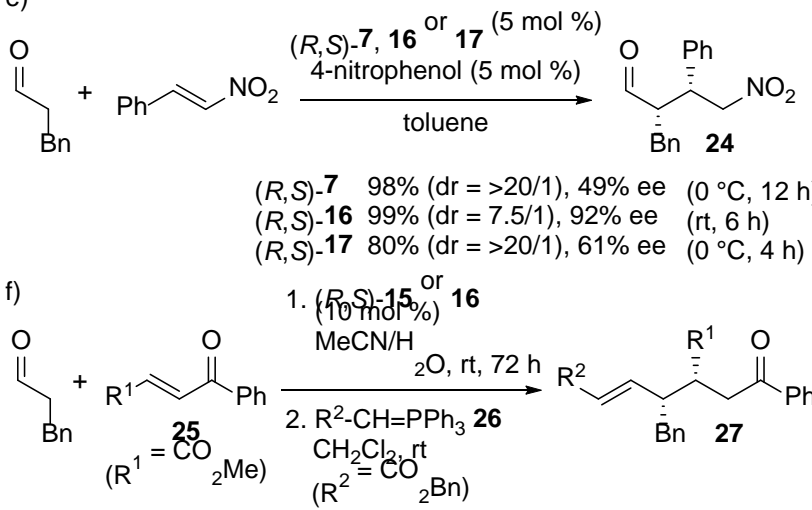

$(R, S)-1583 \%(\mathrm{dr}=>20 / 1), 93 \%$ ee $(R, S)-16$ 99\% $(\mathrm{dr}=11 / 1), 95 \%$ ee

Possible transition state models for the amine-catalyzed Mannich reactions are proposed as shown in Figure 3. In the case of the proline-catalyzed reaction, the syn-isomer is obtained through the s-trans-enamine (Figure 3, TS1). While both strans-enamine and s-cis-enamine might be formed in the reaction catalyzed by $(S)$-2, only s-cis-enamine can react with the imine that is activated by the distal acidic proton of the triflamide of $(S)$-2, giving the unusual anti-isomer predominantly (Figure 3, TS2). On the basis of the observed stereochemical outcome, the reaction catalyzed by $(R, S)-\mathbf{1 4}$, which is a pseudoenantiomer of $(S)$-2, would proceed through a similar transition state TS3, thus affording the anti-product.

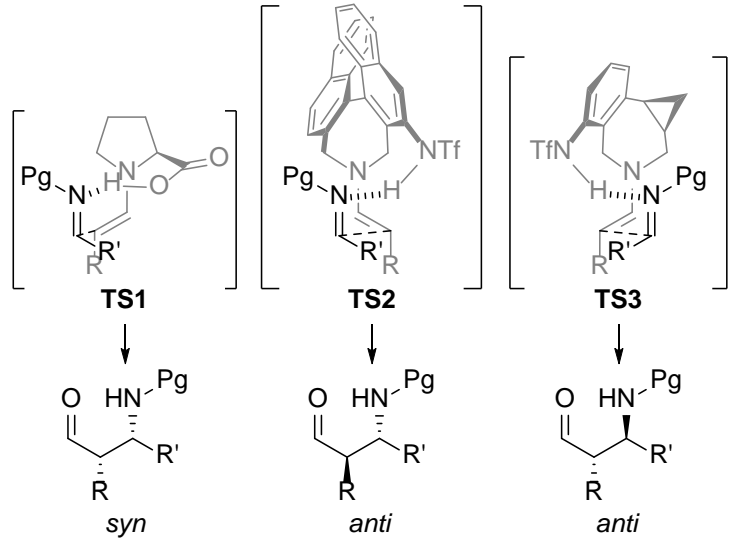

Figure 3. Proposed transition state models for the amine-catalyzed Mannich reactions.

Possible transition state models for the amine-catalyzed aminoxylation and hydroxyamination are also proposed as shown in Figure 4 . In the case of the aminoxylation catalyzed by $(R, S)$ $\mathbf{1 4}$, the observed stereochemistry was rationalized by the transition state model in which nitrosobenzene approaches the $R e$ face of the s-cis-enamine, as directed by the highly acidic triflamide group (TS4). The present aminoxylation might proceed through the acid-base complexation between the triflamide group and the nitroso group that makes the oxygen atom of nitrosobenzene more reactive. On the other hand, the less acidic hydroxy group of $(R, S)-\mathbf{1 5}$ directs and activates nitrosobenzene by hydrogen bonding with the oxygen atom of the nitroso group to give the hydroxyamination product with the $R$ configuration (TS5). In the absence of the highly acidic functionality such as triflamide group, the nitrogen atom of nitrosobenzene is basically more reactive than the oxygen atom because of the higher electronegativity of oxygen atom. We assumed that the acidity of the hydroxy group of $(R, S)-\mathbf{1 5}$ is not enough to form the acidbase complex and the hydroxyamination would proceed instead through TS5 utilizing hydrogen bonding.

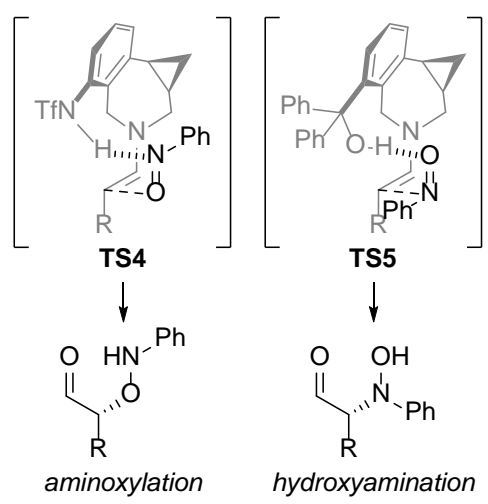

Figure 4. Proposed transition state models for the amine-catalyzed aminoxylation and hydroxyamination.

The newly developed amine catalysts having no $\alpha$-substituent can generate both s-trans and s-cis-enamine intermediates as shown in Figure 5. The conjugate addition catalyzed by $(R, S)$ $\mathbf{1 6}$ seems to proceed through TS6 because of the greater steric repulsion between the catalyst cyclopropane moiety and the acyl group of electron-deficient olefin in TS7 compared to that in TS6. 


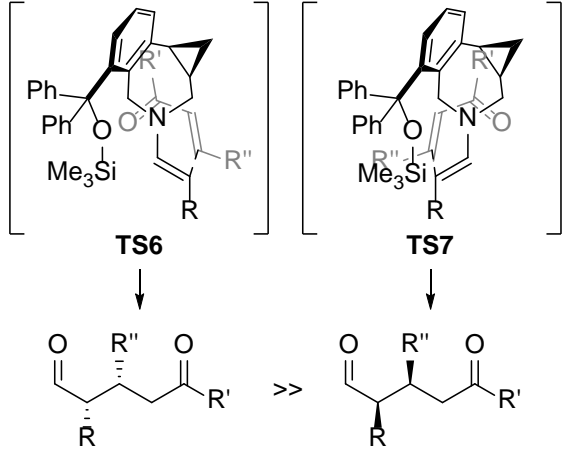

Figure 5. Proposed transition state models for the amine-catalyzed conjugate addition.

In summary, we have developed chiral secondary amine catalysts based on a phenylcyclopropane scaffold as a novel chiral motif. The new design of amine catalysts enabled us to synthesize various types of amine organocatalysts in an efficient way. Research is currently underway to explore the advantages of these phenylcyclopropane-based secondary amines in asymmetric catalysis.

\section{ASSOCIATED CONTENT}

\section{Supporting Information}

The Supporting Information is available free of charge on the ACS Publications website.

Experimental procedures and spectral data for all new compounds (PDF)

\section{AUTHOR INFORMATION}

\section{Corresponding Author}

*E-mail: maruoka@kuchem.kyoto-u.ac.jp kano@kuchem.kyotou.ac.jp

\section{Notes}

The authors declare no competing financial interest.

\section{ACKNOWLEDGMENT}

This work was supported by JSPS KAKENHI Grant Numbers JP17H06450, JP26220803 and JP18H01975.

\section{REFERENCES}

(1) (a) Catalytic Asymmetric Synthesis; Ojima, I., Ed.; Wiley-VCH: New York, 2000. (b) Asymmetric Organocatalysis; Berkessel, A.; Gröger H.; Wiley-VCH, Weinheim, 2005. (c) Enantioselective Organocatalysis, Dalko, P. I. ed.; Wiley-VCH, Weinheim, 2007.

(2) (a) Kano, T.; Takai, J.; Tokuda, O.; Maruoka, K. Angew. Chem. Int. Ed. 2005, 44, 3055. (b) Kano, T.; Tokuda, O.; Takai, J.; Maruoka, K. Chem.-Asian. J. 2006, 1, 210.

(3) (a) Kano, T.; Yamaguchi, Y.; Tokuda, O.; Maruoka, K. J. Am. Chem. Soc. 2005, 127, 16408. (b) Kano, T.; Yamaguchi, Y.; Tanaka, Y.; Maruoka, K. Angew. Chem. Int. Ed. 2007, 46, 1738. (c) Kano, T.; Yamaguchi, Y.; Maruoka, K. Angew. Chem. Int. Ed. 2009, 48, 1838. (d) Kano, T.; Yamaguchi, Y.; Maruoka, K. Chem.-Eur. J. 2009, 15, 6678. (e) Kano, T.; Noishiki, A.; Sakamoto, R.; Maruoka, K. Chem. Commun 2011, 47, 10626. (f) Kano, T.; Sakamoto, R.; Akakura, M.; Maruoka, K. J. Am. Chem. Soc. 2012, 134, 7516. (g) Kano, T.; Sakamoto, R.; Yamaguchi, Y.; Itoh, K.; Maruoka, K. Chem. Commun. 2013, 49, 1118. (h) Kano, T.; Sakamoto, R.; Maruoka, K. Chem. Commun. 2014, 50, 942. (i) Kano, T.; Sakamoto, R.; Maruoka, K. Org. Lett. 2014, 16, 944.
(4) A similar biphenyl-based amine catalyst has also been developed, see: (a) Kano, T.; Sugimoto, H.; Maruoka, K. J. Am. Chem. Soc. 2011, 133, 18130. (b) Kano, T.; Song, S.; Kubota, Y.; Maruoka, K. Angew. Chem. Int. Ed. 2012, 51, 1191. (c) Kano, T.; Song, S.; Maruoka, K. Chem. Commun. 2012, 48, 7037.

(5) Liang, D.-C.; Luo, R.-S.; Yin, L.-H.; Chan, A. S. C.; Lu, G. Org. Biomol. Chem. 2012, 10, 3071.

(6) Kano, T.; Takeda, M.; Sakamoto, R.; Maruoka, K. J. Org. Chem. 2014, 79, 4240. See also ref $2 b$.

(7) Talele, T. T. J. Med. Chem. 2016, 59, 8712.

(8) Boga, S. B.; Alhassan, A. B.; Hesk, D. Tetrahedron Lett. 2014, 55,4442

(9) Chan, K. S. L.; Fu, H.-Y.; Yu, J.-Q. J. Am. Chem. Soc. 2015, 137, 2042.

(10) Wolfe, J. P.; Åhman, J.; Sadighi, J. P.; Singer, R. A.; Buchwald, S. L. Tetrahedron Lett. 1997, 38, 6367.

(11) Kano, T.; Yamamoto, A.; Shirozu, F.; Maruoka, K. Synthesis 2009, 1557.

(12) The crystal structure of $(S)-2$ is inverted to $(R)-2$ for ease of comparison.

(13) (a) Córdova, A.; Watanabe, S.; Tanaka, F.; Notz, W.; Barbas, C. F., III. J. Am. Chem. Soc. 2002, 124, 1866. (b) Hayashi, Y.; Tsuboi, W.; Ashimine, I.; Urushima, T.; Shoji, M.; Sakai, K. Angew. Chem. Int. Ed. 2003, 42, 3677. (c) Cobb, A. J. A.; Shaw, D. M.; Ley, S. V. Synlett 2004, 558. (d) Córdova, A. Chem.-Eur. J. 2004, 10, 1987. (e) Yang, J. W.; Stadler, M.; List, B. Angew. Chem. Int. Ed. 2007, 46, 609. See also: (f) Franzen, J.; Marigo, M.; Fielenbach, D.; Wabnitz, T. C.; Kjærsgaard, A.; Jørgensen, K. A. J. Am. Chem. Soc. 2005, 127, 18296. (g) Mitsumori, S.; Zhang, H.; Cheong, P. H.-Y.; Houk, K. N.; Tanaka, F.; Barbas, C. F., III. J. Am. Chem. Soc. 2006, 128, 1040.

(14) (a) Brown, S. P.; Brochu, M. P.; Sinz, C. J.; MacMillan, D. W. C. J. Am. Chem. Soc. 2003, 125, 10808. (b) Zhong, G. Angew. Chem. Int. Ed. 2003, 42, 4247. (c) Hayashi, Y.; Yamaguchi, J.; Hibino, K.; Shoji, M. Tetrahedron Lett. 2003, 44, 8293. (d) Hayashi, Y.; Yamaguchi, J.; Sumiya, T.; Shoji, M. Angew. Chem. Int. Ed. 2004, 43, 1112. (e) Momiyama, N.; Torii, H.; Saito, S.; Yamamoto, H. Proc. Natl. Acad. Sci. U. S. A. 2004, 101, 5374.

(15) Kano, T.; Yamamoto, A.; Maruoka, K. Tetrahedron Lett. 2008, 49, 5369. See also ref 11.

(16) Kano, T.; Ueda, M.; Takai, J.; Maruoka, K. J. Am. Chem. Soc. 2006, 128, 6046.

(17) (a) Palomo, C.; Vera, S.; Velilla, I.; Mielgo, A.; Gómez-Bengoa, E. Angew. Chem. Int. Ed. 2007, 46, 8054. (b) Macharia, J.; Wambua, V.; Hong, Y.; Harris, L.; Hirschi, J. S.; Evans, G. B.; Vetticatt, M. J. Angew. Chem. Int. Ed. 2017, 56, 8756.

(18) For selected examples of amine-catalyzed conjugate additions of aldehydes to nitroalkenes, see: (a) Betancort, J. M.; Barbas, C. F., III. Org. Lett. 2001, 3, 3737. (b) Alexakis, A.; Andrey, O. Org. Lett. 2002, 4, 3611. (c) Wang, W.; Wang, J.; Li, H. Angew. Chem. Int. Ed. 2005, 44, 1369. (d) Hayashi, Y.; Gotoh, H.; Hayashi, T.; Shoji, M. Angew. Chem. Int. Ed. 2005, 44, 4212. (e) Mase, N.; Watanabe, K.; Yoda, H.; Takabe, K.; Tanaka, F.; Barbas, C. F., III. J. Am. Chem. Soc. 2006, 128, 4966. (f) Zhu, S.; Yu, S.; Ma, D. Angew. Chem. Int. Ed. 2008, 47, 545. (g) Chi, Y.; Guo, L.; Kopf, N.; Gellman, S. H. J. Am. Chem. Soc. 2008, 130, 5608. (h) Wiesner, M.; Revell, J. D.; Wennemers, H. Angew. Chem. Int. Ed. 2008, 47, 1871. (i) Garcia-Garcia, P.; Ladepeche, A.; Halder, R.; List, B. Angew. Chem. Int. Ed. 2008, 47, 4719. (j) Hayashi, Y.; Itoh, T.; Ohkubo, M.; Ishikawa, H. Angew. Chem, Int. Ed. 2008, 47, 4722. (k) Guo, L.; Chi, Y.; Almeida, A. M.; Guzei, L. A.; Parker, B. K.; Gellman, S. H. J. Am. Chem. Soc. 2009, 131, 16018. (l) Wiesner, M.; Upert, G.; Angelici, G.; Wennemers, H. J. Am. Chem. Soc. 2010, 132, 6. (m) Zheng, Z.; Perkins, B. L.; Ni, B. J. Am. Chem. Soc. 2010, 132, 50. See also: (n) Sulzer-Mosse, S.; Alexakis, A. Chem. Commun. 2007, 3123.

(19) (a) Wang, J.; Ma, A.; Ma, D. Org. Lett. 2008, 10, 5425. (b) Kan, S. B. J.; Maruyama, H.; Akakura, M.; Kano, T.; Maruoka, K. Angew. Chem. Int. Ed. 2017, 56, 9487. 
